\title{
Impact of bariatric surgery on periodontal status in an obese cohort at one year of follow-up
}

\author{
SILIE ARBOLEDA ${ }^{1}$, ROQUELINA PIANETA ${ }^{2}$, MIGUEL VARGAS ${ }^{1}$, GLORIA INÉS LAFAURIE $^{3}$, \\ FANNY ALDANA-PARRA ${ }^{4}$ and CARLOS FELIPE CHAUX ${ }^{4}$
}

\author{
${ }^{1}$ School of Dentistry, Unit of Clinical Oral Epidemiology Investigations-UNIECLO, El Bosque University, Bogotá 110121; \\ ${ }^{2}$ School of Dentistry, Rafael Núñez University Corporation, Cartagena 130001; ${ }^{3}$ School of Dentistry, \\ Unit of Basic Oral Investigation-UIBO, El Bosque University; ${ }^{4}$ Obesity Surgery Clinic, Bogotá 110121, Colombia
}

Received February 26, 2021; Accepted June 10, 2021

DOI: $10.3892 / \mathrm{mi} .2021 .4$

\begin{abstract}
The effect of weight loss on the periodontal condition remains unclear. The present prospective study thus aimed to evaluate the effect of weight loss on the periodontal status of 57 obese patients $\left(B M I \geq 30 \mathrm{~kg} / \mathrm{m}^{2}\right.$ ) with ages ranging from 18 to 60 years, at 12 months following bariatric surgery. Demographic, biological and behavioral variables were analyzed. All participants underwent a periodontal examination, including plaque index (PI), bleeding on probing (BOP), pocket depth (PD) and clinical attachment level (CAL). Anthropometric measurements, such as weight, height and body mass index (BMI) were calculated. Fisher's exact test, ANOVA, Bonferroni, Spearman's rank correlation and Wilcoxon signed-rank tests were used for the statistical analysis $(\mathrm{P}<0.05)$. Prior to surgery, $49 \%$ of patients were classified as having obesity class I, $33 \%$ as obesity class II and $18 \%$ as obesity class III. Variables, such as BMI and PD exhibited statistically significant differences among the obesity class I, II and III groups $(\mathrm{P}<0.05)$. As regards periodontal diagnosis, $37 \%$ of patients were classified as having gingivitis, $46 \%$ as having periodontitis stages I-II, and $17 \%$ as having periodontitis stages III-IV. BMI, PI, BOP and PD exhibited statistically significant differences following bariatric surgery $(\mathrm{P}<0.0001)$. No statistically significant differences were observed in the CAL ( $P>0.05)$. Thus, the findings of the present study suggest that weight loss was associated with decreased periodontal inflammation and an improved plaque control following bariatric surgery. CAL remained unaltered during the study period.
\end{abstract}

Correspondence to: Dr Silie Arboleda, School of Dentistry, Unit of Clinical Oral Epidemiology Investigations-UNIECLO, El Bosque University, Ak. 9 \# 131A-20, Bogotá 110121, Colombia

E-mail: siliesoad@gmail.com

Key words: bariatric surgery, body mass index, obesity, periodontitis, prospective studies

\section{Introduction}

Obesity involves the abnormal or excessive accumulation of fat in the body that impairs the health of affected individuals (1). The etiology of obesity involves a myriad of genetic, cultural and societal factors (2). The American Medical Association officially recognized obesity as a human disease in 2013, in order to increase awareness of the condition and due to its associated severe comorbidities, to provide effective treatment options, to reduce mortality and costs (2). Obesity continues to be a risk factor for chronic health conditions, such as hypertension, coronary heart disease, type 2 diabetes, stroke, metabolic syndrome, dyslipidemia and certain types of cancer $(2,3)$. Obesity is also associated with chronic periodontitis (4). Obesity has several harmful biological effects that have been associated with the pathogenesis of periodontitis (5). The most important mediators related to this association are tumor necrosis factor- $\alpha$ (TNF- $\alpha$ ) and interleukin-6 (IL-6). These pro-inflammatory cytokines may exert pleiotropic effects, altering the activities of leukocytes, osteoblasts and osteoclasts (6). Hence, increased levels of pro-inflammatory biomarkers may promote the tissue remodeling process, causing periodontal tissue destruction (6).

The prevalence of obesity continues to increase significantly in developed and developing countries worldwide (7). In 2017-2018, the age-adjusted prevalence of obesity in adults was $42 \%$ (8). It has been projected that by 2030 , up to $58 \%$ of the world's adult population could be either overweight or obese (7).

However, to date, there is no indication of how to prevent the disease efficiently (9). Diet, medications and exercise alone are often ineffective as methods for adults with obesity to achieve long-term weight loss (9). High-quality evidence indicates that bariatric surgery is considered the most effective long-term treatment for severe obesity in individuals with a body mass index $(\mathrm{BMI}) \geq 40 \mathrm{~kg} / \mathrm{m}^{2}$ or $\geq 35 \mathrm{~kg} / \mathrm{m}^{2}$ in those with obesity-related comorbidities (3). The benefits of bariatric surgery include significant and durable weight loss, and an improvement or remission in comorbidities, including hypertension, type 2 diabetes, lipid abnormalities, sleep apnea and depression, thus improving the quality of life of patients and reducing the mortality rate $(10,11)$. 
Evidence related to the effects of bariatric surgery in the periodontal condition has provided conflicting results (12-16). Previous studies have found a negative effect of bariatric surgery on periodontal status $(12,13)$, whereas others have demonstrated an improvement in the periodontal condition following bariatric surgery (16). The present study thus aimed to evaluate the effects of weight loss on the periodontal status of obese patients recommended for bariatric surgery. Considering that bariatric surgery leads to an overall improvement of general inflammation via a decrease in the levels of pro-inflammatory markers (17), it could be hypothesized that bariatric surgery may improve the periodontal status in obese untreated individuals at the follow-up at 12 months.

\section{Patients and methods}

Ethical considerations. The present study was approved by the Ethics Committee of El Bosque University, Bogotá, Colombia (decision no. 003-2014) and was conducted in accordance with the ethical standards of El Bosque University, Bogotá, Colombia, and with the 1964 Helsinki declaration. Individual written consent was obtained from all patients included in the study.

Sample size calculation. The sample size calculation took into consideration parameters based on a previous study that evaluated oral health conditions before and after bariatric surgery (13). With an $\alpha$ error of $5 \%(\alpha=0.05), 90 \%$ power $(\beta=0.10)$ and the difference between two means of probing depth with repeated measures [mean 1, 1.86; standard deviation (SD), 0.44; mean 2, 2.11; SD, 0.38], a sample size of 57 patients was used.

Study design and participants. The present prospective study evaluated obese patients with a BMI $\geq 30 \mathrm{~kg} / \mathrm{m}^{2}$ who were recommended for bariatric surgery and monitored in a reference center in Bogotá, Colombia. From June, 2014 to June, 2016, 70 obese patients were evaluated considering a dropout of $20 \%$ during the study period. A total of 57 patients were followed-up at 12 months following bariatric surgery and were considered for analysis. According to previous studies, the follow-up time of 12 months was determined to represent a period of significant physiological and psychological changes following bariatric surgery $(11,18)$. The inclusion criteria included the following: i) An age between 18 and 60 years; and ii) obese patients with a BMI $\geq 30 \mathrm{~kg} / \mathrm{m}^{2}$ recommended for bariatric surgery (19). The present study excluded individuals with the following conditions: i) Those who were receiving orthodontic treatment; ii) those with $<12$ teeth; iii) those who had received periodontal treatment over the last 3 months; and iv) those who had received antibiotic or anti-inflammatory treatment over the last 3 months.

Sociodemographic data and the systemic condition. A structured questionnaire was administered to each participant to obtain sociodemographic data, knowledge related to oral health and medical aspects of the participant's health. Sociodemographic data included age, sex, social stratification and the education level measured in years. Oral hygiene habits, including the frequency of brushing and flossing, as well as oral hygiene instructions, were collected. Risk indicators, such as gingival bleeding and smoking status were self-reported and collected. Smoking status was defined as current smoker, former smoker, or non-smoker. Participants were asked whether they were ever diagnosed with diabetes or hypertension and whether they were on any medications at the time of the study. The diagnosis was confirmed by medical records. Laboratory information, such as triglyceride and glucose levels were obtained from medical records. The reference values were provided by the laboratories: $\leq 150 \mathrm{mg} / \mathrm{dl}$ for triglyceride levels and $\leq 100 \mathrm{mg} / \mathrm{dl}$ for glucose levels.

Anthropometric measurements. Anthropometric measurements of the individuals, including weight, height and BMI (kilograms divided by the square of height in meters), were measured by a trained and calibrate nutritionist and the individuals wore light clothing and no shoes. Height was registered using a portable stadiometer (SECA 230) and weight was registered using a digital scale (JCM reference WSP 12). The BMI was calculated according to the World Health Organization obesity guide and categorized as follows: Obesity level I, 30 to 34.9 ; obesity level II, 35 to 39.9 ; and obesity level III, $\geq 40$ (1). The indication for bariatric surgery followed the guidelines from the Position Statements from the International Federation for the Surgery of Obesity and Metabolic Disorders (19).

Oral clinical examination. The clinical periodontal examination was performed by two periodontists, who were trained and calibrated prior to the commencement of the study. The examiners evaluated 84 dental surfaces randomly selected from patients unrelated to the study with measurements of probing depth (PD) and clinical attachment level (CAL) repeated at 7-day intervals. The inter-examiner agreement yielded an intraclass correlation coefficient (ICC) of 0.82 which indicates good reliability.

A manual periodontal probe (PCP-UNC 15, Hu-Friedy) was used for the clinical examination of all present teeth (except for third molars), which measured plaque index (PI), bleeding on probing (BOP), PD and CAL. Plaque index assessment was determined using the absence (classified as 0 ) or presence (classified as 1) of dental plaque according to the study by Ainamo and Bay (20). A total of six sites per tooth were evaluated for PD and CAL (mesiobuccal, midbuccal, distobuccal, mesiolingual, midlingual and distolingual). PD was determined by measuring the distance from the gingival margin to the bottom of the gingival crevice in millimeters. CAL was measured as the distance from the cement-enamel junction to the bottom of the gingival crevice in millimeters. For the present study, the periodontal status was assessed according to the World Workshop on Classification of Periodontal and Peri-implant Diseases and Conditions (21).

Intervention and follow-up program. Sleeve gastrectomy (SG) and Roux-en-Y gastric bypass (RYGB) were standardized at the Obesity Surgery Clinic, Bogotá, Colombia, and all procedures were performed laparoscopically. All patients were assessed as part of a routine follow-up program at the reference center and were observed every 3 months by a multidisciplinary team that included BMI collection and nutritional assessment. A 
complete periodontal examination was performed before and 12 months following bariatric surgery with no oral hygiene instructions provided to the patients.

Statistical analysis. The characteristics of the participants were described using frequency distribution for categorical variables, as well as the mean and SD for continuous variables. The Shapiro-Wilk test was performed to analyze the normality of continuous variables. Fisher's exact test were used to determine the differences in sociodemographic characteristics, risk indicators, type of obesity and systemic condition at baseline categorized by the periodontal status. One-way ANOVA was used to compare BMI, laboratory examination results and periodontal status at baseline in the groups in relation to the obesity categorization. Post-hoc comparisons (Bonferroni test) were used with the variables that exhibited statistically significant results, in order to establish where the differences occurred among different groups in relation to the obesity classification. A Spearman's rank correlation was run to assess the correlation between BMI and periodontal clinical parameters (PI, BOP, PD and CAL). The Wilcoxon signed-rank test was used to verify the differences between the two groups (before and after bariatric surgery). All statistical tests were performed using STATA version 13 statistical software and P-values $<0.05$ were considered to indicate statistically significant differences.

\section{Results}

Preoperative evaluation: Before bariatric surgery. A total of 70 obese patients were initially screened for the present study and 57 were followed-up at 12 months. Table I presents the periodontal condition at baseline in relation to the following sociodemographic variables: Sex, age, social stratification, education years and other variables, such as tooth brushing, dental floss, oral hygiene instruction, gingival bleeding, smoking, type of obesity, diabetes and hypertension. As regards periodontal diagnosis the following were observed: $37 \%$ of patients were classified with gingivitis $(n=21), 46 \%$ with periodontitis stages I-II $(n=26)$ and $17 \%$ with periodontitis stages III-IV $(n=10)$. A high frequency of females $(74 \%$, $\mathrm{n}=42$ ), individuals with an average age between 26 to 45 years $(49 \%, n=28)$, individuals classified with a high social stratification $(53 \%, \mathrm{n}=30)$ and with $>12$ years of education $(86 \%$, $\mathrm{n}=49$ ) were noted. As regards oral habits, the following were observed: $100 \%$ of patients brushed their teeth $\geq 2$ times/day, $70 \%$ of patients used dental floss and $96 \%$ had previously received oral hygiene instructions. Variables such as age, gingival bleeding (self-reported) and hypertension exhibited statistically significant differences among the individuals with gingivitis, periodontitis stages I-II and periodontitis stages III-IV $(\mathrm{P}<0.05)$.

Table II presents the anthropometric variables. Prior to surgery, $49 \%$ of patients were classified as having obesity class I $(n=28), 33 \%$ as having obesity class II $(n=19)$ and $18 \%$ as having obesity class III $(\mathrm{n}=10)$. The PD and CAL values were $2.34 \pm 0.40$ and $0.92 \pm 0.61$, respectively and were higher among the patients with obesity class III. The results demonstrated that $56 \%$ of teeth had BOP and $52 \%$ had dental plaque. Variables, such as BMI and PD exhibited statistically significant differences among the patients with obesity class I, II and III groups $(\mathrm{P}<0.05)$. The results of Spearman's correlation analysis indicated that there was a weak positive correlation between BMI and CAL, which was statistically significant, $r s=0.2825, \mathrm{P}=0.033$ (data not shown). The other periodontal parameters (PI, BOP and PD) did not exhibit a correlation with $\mathrm{BMI}(\mathrm{rs} \approx 0.0, \mathrm{P}>0.05)$.

Post-operative evaluation: After 12 months of bariatric surgery. Out of the 70 patients, 8 patients lived outside of the country and thus it was not possible to contact them. Three patients did not undergo bariatric surgery and two had not completed the time frame of 12 months after bariatric surgery. Thus, the final analysis comprised 57 patients: $74 \%$ were females $(n=42)$ and $26 \%$ were males $(n=15)$. SG was performed in $58 \%$ of the patients $(n=33)$ and RYGB on the $42 \%$ of patients $(n=24)$. Data comparing the variable values before and after surgery are presented in Table III. Following surgery, statistically significant differences were observed in BMI, PI, BOP and PD $(\mathrm{P}<0.0001)$. No statistically significant differences were observed in CAL $(\mathrm{P}>0.05)$.

\section{Discussion}

Obesity and periodontitis are two of the most common chronic diseases affecting population worldwide (22). The real mechanisms that link obesity and periodontitis however, remain unknown. However, a number of plausible biological pathways that support the association have been suggested such as low-grade systemic inflammation that has been proposed as a potential causative factor for several conditions including periodontitis (5).

Bariatric surgery is considered an achieving method for long-term and meaningful weight loss in individuals in which non-surgical treatment options were unsuccessful for weight reduction (23). Bariatric procedures have exhibited effective improvement in the quality of life of these patients by inducing a remission in initial type 2 diabetes, the reduction of hypertension and obstructive sleep apnea $(10,23)$. The epidemiological evidence confirms an increase in obesity in both sexes and all ages regardless of ethnicity, geographical locality, or socioeconomic status, even though the prevalence of obesity is generally greater in older individuals and women (24). The sample cohort of the present study consisted of mostly females (74\%) and this is justified by the fact that women are undergoing bariatric procedures more frequently than men, corroborating the findings of several studies $(10,25)$.

In the present study, the average values of PD and CAL were significantly higher in subjects with obesity class III $(\mathrm{P}<0.05)$ when compared with those in subjects with obesity class I and II. This result was consistent with the findings of the study conducted by Morita et al (26), who demonstrated a dose-response association between BMI and the development of periodontitis. The present study demonstrated that there was a weak positive significant correlation between BMI and CAL in the bivariate analysis. This result was in agreement with the findings of other studies $(27,28)$. Although CAL is considered one of the clinical signs of periodontitis, it may occur in the absence of this disease (21). More specifically, CAL is an indicator of a history of periodontal disease. 
Table I. Sociodemographic data and systemic conditions in relation to periodontal status at baseline.

\begin{tabular}{|c|c|c|c|c|c|}
\hline Variable & $\begin{array}{c}\text { Total } \\
\mathrm{n}=57(100 \%)\end{array}$ & $\begin{array}{c}\text { Gingivitis } \\
\mathrm{n}=21(37 \%)\end{array}$ & $\begin{array}{c}\text { Periodontitis } \\
\text { stages I-II } \\
n=26(46 \%)\end{array}$ & $\begin{array}{l}\text { Periodontitis } \\
\text { stages III-IV } \\
\mathrm{n}=10(17 \%)\end{array}$ & P-value \\
\hline \multicolumn{6}{|l|}{ Age, years } \\
\hline$\leq 25$ & $15(26)$ & $7(33)$ & $8(31)$ & $0(0)$ & \multirow[t]{3}{*}{$0.031^{\mathrm{a}}$} \\
\hline$<26$ to $\leq 45$ & $28(49)$ & $9(43)$ & $15(58)$ & $4(40)$ & \\
\hline$>45$ & $14(25)$ & $5(24)$ & $3(11)$ & $6(60)$ & \\
\hline \multicolumn{6}{|l|}{ Sex } \\
\hline Female & $42(74)$ & $13(62)$ & $22(85)$ & $7(70)$ & \multirow[t]{2}{*}{0.227} \\
\hline Male & $15(26)$ & $8(38)$ & $4(15)$ & $3(30)$ & \\
\hline \multicolumn{6}{|l|}{ Social stratification } \\
\hline Low & $3(5)$ & $0(0)$ & $1(4)$ & $2(20)$ & \multirow[t]{3}{*}{0.301} \\
\hline Medium & $24(42)$ & $10(48)$ & $10(38)$ & $4(40)$ & \\
\hline High & $30(53)$ & $11(52)$ & $15(58)$ & $4(40)$ & \\
\hline \multicolumn{6}{|c|}{ Education level (years) } \\
\hline$\leq 12$ & $8(14)$ & $2(10)$ & $2(8)$ & $4(40)$ & \multirow[t]{2}{*}{0.064} \\
\hline$>12$ & $49(86)$ & $19(90)$ & $24(92)$ & $6(60)$ & \\
\hline \multicolumn{6}{|l|}{ Tooth brushing } \\
\hline 2 times/day & $21(37)$ & $11(52)$ & $9(35)$ & $1(10)$ & \multirow[t]{2}{*}{0.056} \\
\hline$\geq 3$ times/day & $36(63)$ & $10(48)$ & $17(65)$ & $9(90)$ & \\
\hline \multicolumn{6}{|l|}{ Dental floss } \\
\hline Non-users & $17(30)$ & $7(33)$ & $6(23)$ & $4(40)$ & \multirow[t]{2}{*}{0.549} \\
\hline Users & $40(70)$ & $14(67)$ & $20(77)$ & $6(60)$ & \\
\hline \multicolumn{6}{|c|}{ Oral hygiene instruction } \\
\hline Yes & $55(96)$ & $20(95)$ & $26(100)$ & $9(90)$ & \multirow[t]{2}{*}{0.291} \\
\hline No & $2(4)$ & $1(5)$ & $0(0)$ & $1(10)$ & \\
\hline \multicolumn{6}{|l|}{ Gingival bleeding } \\
\hline Yes & $32(56)$ & $13(62)$ & $11(42)$ & $1(10)$ & \multirow[t]{2}{*}{$0.019^{\mathrm{a}}$} \\
\hline No & $25(44)$ & $8(38)$ & $15(58)$ & $9(90)$ & \\
\hline \multicolumn{5}{|l|}{ Smoking status } & \multirow[t]{4}{*}{0.277} \\
\hline Smokers & $6(10)$ & $2(10)$ & $2(8)$ & $2(20)$ & \\
\hline Former smokers & $5(9)$ & $4(19)$ & $1(4)$ & $0(0)$ & \\
\hline Non-smokers & $46(81)$ & $15(71)$ & $23(88)$ & $8(80)$ & \\
\hline \multicolumn{6}{|l|}{ Obesity } \\
\hline Type I & $28(49)$ & $9(43)$ & $15(58)$ & $4(40)$ & \multirow[t]{3}{*}{0.066} \\
\hline Type II & $19(33)$ & $11(52)$ & $6(23)$ & $2(20)$ & \\
\hline Type III & $10(18)$ & $1(5)$ & $5(19)$ & $4(40)$ & \\
\hline \multicolumn{6}{|l|}{ Diabetes } \\
\hline Yes & $5(9)$ & $2(10)$ & $1(4)$ & $2(20)$ & \multirow[t]{2}{*}{0.242} \\
\hline No & $52(91)$ & $19(90)$ & $25(96)$ & $8(80)$ & \\
\hline \multicolumn{6}{|l|}{ Hypertension } \\
\hline Yes & $7(12)$ & $2(10)$ & $1(4)$ & $4(40)$ & \multirow[t]{2}{*}{$0.020^{\mathrm{a}}$} \\
\hline No & $50(88)$ & $19(90)$ & $25(96)$ & $6(60)$ & \\
\hline
\end{tabular}

Gingival bleeding was self-reported. ${ }^{\mathrm{P}}<0.05$, indicates statistical significance, as determined by Fisher's exact test.

Therefore, the strength of the association between periodontitis and obesity may be overestimated due to the definitions used to describe periodontitis in the literature (29). The present study found a positive impact of bariatric surgery on periodontal status at the follow-up at 12 months. There was a decrease in periodontal inflammation with changes observed regarding $\mathrm{PD}$ and the presence of sites with detectable plaque and bleeding; however, these findings contradict the outcomes 
Table II. Characteristics of participants in relation to BMI at baseline.

\begin{tabular}{|c|c|c|c|c|c|}
\hline Variable & $\begin{array}{c}\text { Total } \\
\mathrm{n}=57(100 \%) \\
\text { mean }(\mathrm{SD})\end{array}$ & $\begin{array}{c}\text { Obesity I } \\
\mathrm{n}=28(49 \%) \\
\text { mean }(\mathrm{SD})\end{array}$ & $\begin{array}{c}\text { Obesity II } \\
\mathrm{n}=19(33 \%) \\
\text { mean }(\mathrm{SD})\end{array}$ & $\begin{array}{c}\text { Obesity III } \\
\mathrm{n}=10(18 \%) \\
\text { mean }(\mathrm{SD})\end{array}$ & P-value \\
\hline Age (years) & $35.40(12.42)$ & $34.25(12.45)$ & $36.21(13.34)$ & $37.1(11.41)$ & 0.782 \\
\hline BMI $\left(\mathrm{kg} / \mathrm{m}^{2}\right)$ & $35.29(4.43)$ & $31.66^{\mathrm{b}}(1.36)$ & $36.68^{\mathrm{b}}(1.37)$ & $42.79^{b}(2.34)$ & $0.001^{\mathrm{a}}$ \\
\hline Triglycerides & $137.38(51.44)$ & $132.85(54.77)$ & $140.26(53.27)$ & $144.6(40.65)$ & 0.795 \\
\hline Glycaemia & $97.33(17.45)$ & $94.53(17.37)$ & $98.63(17.14)$ & $102.7(18.50)$ & 0.420 \\
\hline PI (\% surfaces) & $52.26(22.42)$ & $55.39(22.56)$ & $46.84(22.83)$ & $53.8(21.50)$ & 0.434 \\
\hline BOP (\% surfaces) & $55.91(21.78)$ & $56.67(22.68)$ & $50.68(19.47)$ & $63.7(22.86)$ & 0.305 \\
\hline $\mathrm{PD}(\mathrm{mm})$ & $2.34(0.40)$ & $2.29(0.30)$ & $2.20(0.25)$ & $2.74^{\mathrm{b}}(0.63)$ & $0.001^{\mathrm{a}}$ \\
\hline CAL (mm) & $0.92(0.61)$ & $0.77(0.51)$ & $1.00(0.68)$ & $1.21(0.65)$ & 0.119 \\
\hline No. of missing teeth & $3.10(3.60)$ & $2.57(2.80)$ & $4(4.77)$ & $2.8(2.93)$ & 0.374 \\
\hline
\end{tabular}

${ }^{\mathrm{a}} \mathrm{P}<0.05$, determined using ANOVA; ${ }^{\mathrm{b}}<0.05$ post hoc comparisons following ANOVA with the Bonferroni test. BMI, body mass index; PI, plaque index; BOP, bleeding on probing; PD, probing depth; CAL, clinical attachment loss.

Table III. Comparison of BMI and periodontal status before and after bariatric surgery.

\begin{tabular}{|c|c|c|c|c|c|c|c|}
\hline \multirow[b]{2}{*}{ Variable } & \multicolumn{2}{|c|}{ Before $(n=57)$} & \multicolumn{2}{|c|}{ After $(n=57)$} & \multicolumn{2}{|c|}{ Difference } & \multirow[b]{2}{*}{ P-value } \\
\hline & $\begin{array}{l}\text { Mean } \\
(\mathrm{SD})\end{array}$ & $\begin{array}{l}\text { Median } \\
\quad(\text { IR })\end{array}$ & $\begin{array}{l}\text { Mean } \\
(\mathrm{SD})\end{array}$ & $\begin{array}{l}\text { Median } \\
\quad(\text { IR) }\end{array}$ & $\begin{array}{l}\text { Mean } \\
(\mathrm{SD})\end{array}$ & $\begin{array}{l}\text { Median } \\
\quad(\text { IR) }\end{array}$ & \\
\hline BMI $\left(\mathrm{kg} / \mathrm{m}^{2}\right)$ & $\begin{array}{l}35.29 \\
(4.43)\end{array}$ & $\begin{array}{c}34.94 \\
(31.35-37.53)\end{array}$ & $\begin{array}{l}26.51 \\
(3.58)\end{array}$ & $\begin{array}{c}25.8 \\
(24.7-29)\end{array}$ & $\begin{array}{c}8.77 \\
(4.68)\end{array}$ & $\begin{array}{c}8.32 \\
(5.05-11.23)\end{array}$ & $<0.0001^{\mathrm{a}}$ \\
\hline PI (\% surfaces) & $\begin{array}{c}52.26 \\
(22.42)\end{array}$ & $\begin{array}{c}48 \\
(37-66)\end{array}$ & $\begin{array}{c}29.77 \\
(17.06)\end{array}$ & $\begin{array}{c}25 \\
(18-41)\end{array}$ & $\begin{array}{c}22.63 \\
(22.50)\end{array}$ & $\begin{array}{c}23 \\
(9-37)\end{array}$ & $<0.0001^{\mathrm{a}}$ \\
\hline $\mathrm{BOP}$ (\% surfaces) & $\begin{array}{c}55.91 \\
(21.78)\end{array}$ & $\begin{array}{c}50 \\
(41-70)\end{array}$ & $\begin{array}{c}38.01 \\
(20.25)\end{array}$ & $\begin{array}{c}32 \\
(22-48)\end{array}$ & $\begin{array}{c}17.92 \\
(22.39)\end{array}$ & $\begin{array}{c}18 \\
(2-30)\end{array}$ & $<0.0001^{\mathrm{a}}$ \\
\hline $\mathrm{PD}(\mathrm{mm})$ & $\begin{array}{c}2.34 \\
(0.40)\end{array}$ & $\begin{array}{c}2.29 \\
(2.12-2.42)\end{array}$ & $\begin{array}{c}2.25 \\
(0.37)\end{array}$ & $\begin{array}{c}2.23 \\
(2.08-2.37)\end{array}$ & $\begin{array}{c}0.09 \\
(0.21)\end{array}$ & $\begin{array}{c}0.05 \\
(0-0.11)\end{array}$ & $<0.0001^{\mathrm{a}}$ \\
\hline CAL (mm) & $\begin{array}{c}0.92 \\
(0.61)\end{array}$ & $\begin{array}{c}0.94 \\
(0.36-1.3)\end{array}$ & $\begin{array}{c}0.93 \\
(0.56)\end{array}$ & $\begin{array}{c}0.99 \\
(0.38-1.35)\end{array}$ & $\begin{array}{l}-0.01 \\
(0.20)\end{array}$ & $\begin{array}{c}0.01 \\
(-0.07-0.06)\end{array}$ & 1.000 \\
\hline
\end{tabular}

${ }^{a} \mathrm{P}<0.0001$, statistical significance determined by the Wilcoxon signed-rank test. BMI, body mass index; PI, plaque index; BOP, bleeding on probing; PD, probing depth; CAL, clinical attachment loss; SD, standard deviation; IR, interquartile range (IR, 25th-75th percentile).

of previous epidemiological clinical studies that have demonstrated a negative influence of bariatric surgery on periodontal status $(13,14,30)$. Marsicano et al $(12)$, in a cross-sectional study, reported an increase in the number of periodontal pockets associated with bariatric surgery. In another cohort study conducted by de Moura-Grec et al (13), an improvement in clinical systemic conditions was observed at 6 months after bariatric surgery, although PD and CAL exhibited a significant increase after surgery, suggesting an association between the periodontal condition worsening and some consequences of bariatric surgery, such as nutritional deficiency, changes in dietary habits, or unsatisfactory periodontal status of patients prior to surgery. de Carvalho Sales-Peres et al (14), demonstrated a significant association between the reduction of BMI and the increase in BOP, indicating worse indexes at 6 months after surgery, and a slight improvement at the 12-month follow-up. The lack of information on individual oral hygiene habits and socioeconomic factors may have helped to clarify why weight loss would be associated with increased gingival bleeding (14) or if these effects were due to metabolic alterations after bariatric surgery. However, the results found in the present study are in concordance with those of Jaiswal et al (16), who found differences in bleeding score, plaque and gingival index at 6 months after bariatric surgery, which they attributed to changes in diet and oral hygiene instructions provided to patients before bariatric surgery, which appeared to contribute to an improvement in periodontal condition. However, in a recent study, Weinberg et al (15), did not find any changes in the periodontal parameters evaluated (PI, PD, BOP and teeth with calculus) between baseline and at follow-up at 12 months. These results were attributed to the lack of overall awareness to periodontal disease among patients and providers. 
It is well-known that individuals who are better educated and wealthier are more likely to have more positive attitudes regarding self-care and better access to available healthcare options than the marginal segments of society (31). The present study found that all patients brushed their teeth $\geq 2$ times/day, $70 \%$ of patients used dental floss, $96 \%$ had received oral hygiene instructions previously, $86 \%$ had $>12$ years of education and $53 \%$ belonged to a high social stratification status. Weight loss is associated with a significant improvement in the health-related quality of life and a decrease in depressive symptoms following surgery, which could lead individuals becoming more interested in developing health-enhancing habits, including physical activity and healthy nutrition $(10,11)$. Al-Zahrani et al (32) reported that maintaining a normal body weight and a healthy diet along with engaging in physical activity was associated with a $16 \%$ reduction in the prevalence of periodontitis. The characteristics of the population cohort in the present study together with the acquisition of new behavioral patterns to establish a new lifestyle following surgery possibly affected the self-performed plaque control, leading to a lower plaque-index and therefore, to a lower percentage of sites with inflammation. The effect of maintaining good oral hygiene on the periodontium has been well-documented (33). In addition, good oral hygiene practices can favorably influence the ecology of the subgingival microbiota in shallow-to-moderate pockets (31).

Furthermore, if obesity and periodontitis are related through an inflammatory pathway, a significant reduction in adipose tissue observed following bariatric surgery should improve periodontal conditions, at least in terms of inflammation $(17,18)$. It has been shown that the levels of pro-inflammatory biomarkers, such as TNF- $\alpha$ and IL-6, tend to decrease at 6 months following bariatric surgery (17), and this reduction is even higher after 12 months (18). On the other hand, circulating levels of adiponectin, which may have anti-inflammatory properties, have been shown to increase at 12 months following bariatric surgery (18). In the present study, PD exhibited a statistically significant difference before and after surgery; however, although these measurements have a statistically significant difference, the clinical impact could be debatable as the CAL remained unaltered during the study period, indicating that the changes could also have occurred due to a systemic anti-inflammatory effect following bariatric surgery.

Nutritional deficiency is a common complication and one of the side-effects of bariatric surgery (10). SG and RYBG procedures may lead to micronutrient deficiencies, such as iron, vitamin B12, folate, calcium and vitamin D (10). For this reason, the patients in the present study underwent clinical and nutritional monitoring, and were instructed to take supplemental vitamins and minerals to detect and treat any metabolic consequence arising from bariatric procedures. They also were directed to eat slower and avoid discomfort resulting in reflux. The improvement in periodontal conditions at 12 months after bariatric surgery which was observed in the present study and in the study by de Carvalho Sales-Peres et al (14), regarding the first 6 months, could correspond to a period of equilibrium and adaptation of patients to a new lifestyle and the amelioration of the symptoms of any complication related to bariatric surgery when they returned to conventional eating habits and a complete restoration of salivary flow $(30,34)$.
Bariatric procedure practitioners should be aware of potential dental complications following bariatric surgery and counsel their patients with the necessary information and instructions regarding oral hygiene practices, healthy dietetic habits and regular dental examinations.

The fact that it is impossible to determine which factor or factors contributed to the improvements of periodontal status following bariatric surgery, is a limitation of the present study. This supports the need for additional high-quality studies and promotes further research in this area by multidisciplinary teams.

In conclusion, the findings of the present study suggest that weight loss was associated with decreased periodontal inflammation and better plaque control following bariatric surgery. Clinical attachment loss remained unchanged during the study period.

\section{Acknowledgements}

The authors would like to thank Clínica de Cirugía para la Obesidad for their support in obtaining the information related to patients included in the present study.

\section{Funding}

The present study was financed by the Academic Contest Clinical Investigation and Technological Innovation (no. 11678), El Bosque University.

\section{Availability of data and materials}

The datasets used and analyzed during the current study are available from the corresponding author on reasonable request.

\section{Authors' contributions}

SA, RP, MV, GIL, FAP and CFC certify that they have participated sufficiently in the study to take responsibility for the content, including participation in the design, analysis, interpretation of the data, writing and revision of the manuscript, and in the approval of the final version. FAP also performed the anthropometric measurements and provided nutritional advice. CFC also performed all the bariatric surgeries. SA and RP confirm the authenticity of the raw data. All authors have read and approved the final manuscript.

\section{Ethics approval and consent to participate.}

All procedures performed in studies involving human participants were in accordance with the ethical standards of the institutional and national research committee and with the 1964 Helsinki declaration and its later amendments or comparable ethical standards. The study was approved by the Institutional Ethics Committee (decision number: 003-2014) El Bosque University. Individual written consent was obtained from all patients included in the study.

\section{Patient consent for publication}

Not applicable. 


\section{Competing interests}

The authors declare that they have no competing interests.

\section{References}

1. Obesity: preventing and managing the global epidemic. Report of a WHO consultation. World Health Organ Tech Rep Ser 894: i-xii, 1-253, 2000.

2. Bray GA, Kim KK, Wilding JP and World Obesity F; World Obesity Federation: Obesity: A chronic relapsing progressive disease process. A position statement of the World Obesity Federation. Obes Rev 18: 715-723, 2017.

3. Mechanick JI, Kushner RF, Sugerman HJ, Gonzalez-Campoy JM, Collazo-Clavell ML, Spitz AF, Apovian CM, Livingston EH, Brolin R, Sarwer DB, et al: American Association of Clinical Endocrinologists, The Obesity Society, and American Society for Metabolic and Bariatric Surgery medical guidelines for clinical practice for the perioperative nutritional, metabolic, and nonsurgical support of the bariatric surgery patient. Obesity (Silver Spring) 17 (Suppl 1): S1-70, v, 2009.

4. Al-Zahrani MS, Bissada NF and Borawskit EA: Obesity and periodontal disease in young, middle-aged, and older adults. J Periodontol 74: 610-615, 2003.

5. Genco RJ, Grossi SG, Ho A, Nishimura F and Murayama Y: A proposed model linking inflammation to obesity, diabetes, and periodontal infections. J Periodontol 76 (Suppl 11): 2075-2084, 2005.

6. Noh MK, Jung M, Kim SH, Lee SR, Park KH, Kim DH, Kim HH and Park YG: Assessment of IL-6, IL-8 and TNF- $\alpha$ levels in the gingival tissue of patients with periodontitis. Exp Ther Med 6: 847-851, 2013

7. Kelly T, Yang W, Chen CS, Reynolds K and He J: Global burden of obesity in 2005 and projections to 2030. Int J Obes 32 . 1431-1437, 2008

8. Hales CM, Carroll MD, Fryar CD and Ogden CL: Prevalence of Obesity and Severe Obesity Among Adults: United States, 2017-2018. NCHS Data Brief 360: 1-8, 2020.

9. Rosenthal RJ, Morton J, Brethauer S, Mattar S, De Maria E, Benz JK, Titus J and Sterrett D: Obesity in America. Surg Obes Relat Dis 13: 1643-1650, 2017.

10. Castanha CR, Tcbc-Pe AA, Castanha AR, Belo GQ, Lacerda RM and Vilar L: Evaluation of quality of life, weight loss and comorbidities of patients undergoing bariatric surgery. Rev Col Bras Cir 45: e1864, 2018.

11. Kolotkin RL and Andersen JR: A systematic review of reviews: Exploring the relationship between obesity, weight loss and health-related quality of life. Clin Obes 7: 273-289, 2017.

12. Marsicano JA, Sales-Peres A, Ceneviva R and de C Sales-Peres SH: Evaluation of oral health status and salivary flow rate in obese patients after bariatric surgery. Eur J Dent 6: 191-197, 2012

13. de Moura-Grec PG, Yamashita JM, Marsicano JA, Ceneviva R, de Souza Leite CV, de Brito GB, Brienze SL and de Carvalho Sales-Peres SH: Impact of bariatric surgery on oral health conditions: 6-months cohort study. Int Dent J 64: 144-149, 2014.

14. de Carvalho Sales-Peres SH, de Carvalho Sales-Peres M, Passeri CR, Ceneviva R and Bernabe E: Weight loss after bariatric surgery and periodontal changes: a 12-month prospective study. Surgery for obesity and related diseases : official journal of the American Society for Bariatric Surgery 13: 637-642, 2017.

15. Weinberg G, Bilder L, Horwitz J, Pupko M, Mahajna A, Machtei E and Assalia A: Oral health status of patients before and after bariatric surgery. Dent Oral Health Care 1: 1-8, 2018.

16. Jaiswal GR, Jain VK, Dhodapkar SV, Kumathalli KI, Kumar R, Nemawat A and Jain A: Impact of bariatric surgery and diet modification on periodontal status: A six month cohort Study. J Clin Diagn Res 9: ZC43-ZC45, 2015.

17. Miller GD, Nicklas BJ and Fernandez A: Serial changes in inflammatory biomarkers after Roux-en-Y gastric bypass surgery. Surg Obes Relat Dis 7: 618-624, 2011.
18. Illán-Gómez F, Gonzálvez-Ortega M, Orea-Soler I, Alcaraz-Tafalla MS, Aragón-Alonso A, Pascual-Díaz M, Pérez-Paredes M and Lozano-Almela ML: Obesity and inflammation: Change in adiponectin, $\mathrm{C}$-reactive protein, tumour necrosis factor-alpha and interleukin- 6 after bariatric surgery. Obes Surg 22: 950-955, 2012.

19. De Luca M, Angrisani L, Himpens J, Busetto L, Scopinaro N, Weiner R, Sartori A, Stier C, Lakdawala M, Bhasker AG, et al: Indications for Surgery for Obesity and Weight-Related Diseases: Position Statements from the International Federation for the Surgery of Obesity and Metabolic Disorders (IFSO). Obes Surg 26: 1659-1696, 2016 .

20. Ainamo $\mathrm{J}$ and Bay I: Problems and proposals for recording gingivitis and plaque. Int Dent J 25: 229-235, 1975.

21. Papapanou PN, Sanz M,Buduneli N,Dietrich T, Feres M, Fine DH Flemmig TF, Garcia R, Giannobile WV, Graziani F, et al: Periodontitis: Consensus report of workgroup 2 of the 2017 World Workshop on the Classification of Periodontal and Peri-Implant Diseases and Conditions. J Periodontol 89 (Suppl 1): S173-S182, 2018.

22. Linden GJ, Lyons A and Scannapieco FA: Periodontal systemic associations: Review of the evidence. J Clin Periodontol 40 (Suppl 14): S8-S19, 2013.

23. Peterli R, Wölnerhanssen BK, Peters T, Vetter D, Kröll D, Borbély Y, Schultes B, Beglinger C, Drewe J, Schiesser M, et al: Effect of laparoscopic sleeve gastrectomy vs laparoscopic Roux-en-Y gastric bypass on weight loss in patients with morbid obesity: The SM-BOSS Randomized Clinical Trial. JAMA 319: 255-265, 2018.

24. Chooi YC, Ding C and Magkos F: The epidemiology of obesity. Metabolism 92: 6-10, 2019.

25. Pataro AL, Costa FO, Cortelli SC, Cortelli JR, Dupim Souza AC, Nogueira Guimarães Abreu MH, Girundi MG and Costa JE: Influence of obesity and bariatric surgery on the periodontal condition. J Periodontol 83: 257-266, 2012.

26. Morita I, Okamoto Y, Yoshii S, Nakagaki H, Mizuno K, Sheiham A and Sabbah W: Five-year incidence of periodontal disease is related to body mass index. J Dent Res 90: 199-202, 2011.

27. Dalla Vecchia CF, Susin C, Rösing CK, Oppermann RV and Albandar JM: Overweight and obesity as risk indicators for periodontitis in adults. J Periodontol 76: 1721-1728, 2005.

28. Nascimento GG, Peres KG, Mittinty MN, Mejia GC, Silva DA, Gonzalez-Chica D andPeres MA: Obesity and periodontal outcomes: A population-based cohort study in Brazil. J Periodontol 88: 50-58, 2017.

29. Tonetti MS, Greenwell H and Kornman KS: Staging and grading of periodontitis: Framework and proposal of a new classification and case definition. J Clin Periodontol 45 (Suppl 20): S149-S161, 2018.

30. Marsicano JA, Grec PG, Belarmino LB, Ceneviva R and Peres SH: Interfaces between bariatric surgery and oral health: A longitudinal survey. Acta Cir Bras 26 (Suppl 2): 79-83, 2011.

31. Burt B; Research,Science and Therapy Committee of the American Academy of Periodontology: Position paper: Epidemiology of periodontal diseases. J Periodontol 76: 1406-1419, 2005.

32. Al-Zahrani MS, Borawski EA and Bissada NF: Periodontitis and three health-enhancing behaviors: Maintaining normal weight, engaging in recommended level of exercise, and consuming a high-quality diet. J Periodontol 76: 1362-1366, 2005.

33. Axelsson P, Nyström B and Lindhe J: The long-term effect of a plaque control program on tooth mortality, caries and periodontal disease in adults. Results after 30 years of maintenance. J Clin Periodontol 31: 749-757, 2004.

34. Dos Santos MC, Pellizzer EP, SoutoMaior JR, da Silva Casado BG, de Luna Gomes JM, do Egito Vasconcelos BC and Dantas de Moraes SL: Clinical periodontal conditions in individuals after bariatric surgery: A systematic review and meta-analysis. Surg Obes Relat Dis 15: 1850-1859, 2019.

This work is licensed under a Creative Commons Attribution-NonCommercial-NoDerivatives 4.0 International (CC BY-NC-ND 4.0) License. 